\title{
Recent patent applications in antibody fragments
}

\begin{tabular}{|c|c|c|c|c|c|}
\hline Patent number & Description & Assignee & Inventor & $\begin{array}{l}\text { Priority } \\
\text { application } \\
\text { date }\end{array}$ & $\begin{array}{c}\text { Publication } \\
\text { date }\end{array}$ \\
\hline $\begin{array}{l}\text { WO } 2009126730 \text {, } \\
\text { WO } 2009126730\end{array}$ & $\begin{array}{l}\text { A method of preparing nucleotides of single-chain variable fragments } \\
\text { encoding an antigen-specific binding domain by amplifying the variable } \\
\text { regions of the antibody's heavy chain and the lambda and kappa light } \\
\text { chains using PCR with a set of primers. }\end{array}$ & $\begin{array}{l}\text { University of } \\
\text { Pennsylvania } \\
\text { (Philadelphia) }\end{array}$ & Mason N & $4 / 9 / 2008$ & $\begin{array}{l}10 / 15 / 2009 \\
12 / 30 / 2009\end{array}$ \\
\hline US 20090297439 & $\begin{array}{l}\text { An immuno-imaging agent for the detection of a tumor in a subject, } \\
\text { comprising an anti-Met monoclonal antibody, its fragment and a geneti- } \\
\text { cally engineered/humanized antibody containing the epitope binding } \\
\text { region or complementarity-determining regions of the antibody. }\end{array}$ & $\begin{array}{l}\text { Metheresis } \\
\text { Translational } \\
\text { Rsesearch } \\
\text { (Lugano, } \\
\text { Switzerland) }\end{array}$ & $\begin{array}{l}\text { Carminati P, } \\
\text { Comoglio PM, } \\
\text { van Dongen G }\end{array}$ & $6 / 2 / 2008$ & $12 / 3 / 2009$ \\
\hline $\begin{array}{l}\text { FR 2931481, } \\
\text { WO 2009141458 }\end{array}$ & $\begin{array}{l}\text { New isolated antibodies or at least one of their functional fragments, } \\
\text { which is specific to an epitope comprising at least one lysyl compound } \\
\text { useful, e.g., for detecting epitope in a sample in vitro or in vivo. }\end{array}$ & $\begin{array}{l}\text { Covalab } \\
\text { (Villeurbanne, } \\
\text { France) }\end{array}$ & $\begin{array}{l}\text { Ceylan I, } \\
\text { El Alaoui EBS, } \\
\text { Thomas V }\end{array}$ & $5 / 23 / 2008$ & $\begin{array}{l}11 / 27 / 2009, \\
11 / 26 / 2009\end{array}$ \\
\hline WO 2009138714 & $\begin{array}{l}\text { A method for the separation of a fragment antibody, e.g., single-chain } \\
\text { variable fragment, involving contacting a medium containing the fragment } \\
\text { antibody with a synthetic affinity ligand attached to a support matrix under } \\
\text { conditions where the fragment antibody binds to the ligand. }\end{array}$ & $\begin{array}{l}\text { Avecia Biologics } \\
\text { (Manchester, UK) }\end{array}$ & Liddell JM & $5 / 16 / 2008$ & $11 / 19 / 2009$ \\
\hline $\begin{array}{l}\text { FR 2929519, } \\
\text { WO } 2009136031\end{array}$ & $\begin{array}{l}\text { Use of a monoclonal antibody secreted by a hybridoma or its functional } \\
\text { fragments to prepare a medicament to inhibit the growth of a primary } \\
\text { tumor for early cancer treatment where the cancer is, e.g., colon, lung } \\
\text { prostate cancer. }\end{array}$ & $\begin{array}{l}\text { Pierre Fabre } \\
\text { Medicament } \\
\text { (Boulogne, France) }\end{array}$ & Haeuw JF & $4 / 4 / 2008$ & $\begin{array}{l}\text { 10/9/2009, } \\
11 / 12 / 2009\end{array}$ \\
\hline US 20090269277 & $\begin{array}{l}\text { A method for delivering an agent useful for diagnosing or treating, e.g., } \\
\text { cancer or cardiovascular disease, by administering a hexameric stably } \\
\text { tethered structure comprising the agent, an IgG antibody and antibody } \\
\text { fragments or cytokines to the subject. }\end{array}$ & $\begin{array}{l}\text { IBC } \\
\text { Pharmaceuticals } \\
\text { (Morris Plains, NJ, } \\
\text { USA) }\end{array}$ & $\begin{array}{l}\text { Chang C, } \\
\text { Goldenberg DM, } \\
\text { Rossi EA }\end{array}$ & 10/19/2005 & $10 / 29 / 2009$ \\
\hline WO 2009129521 & $\begin{array}{l}\text { An antigen composition for early detection of Mycobacterium tubercu- } \\
\text { losis or immunizing against infection, comprising, e.g., M. tuberculosis } \\
\text { proline threonine repetitive protein fragments having specific sequences } \\
\text { that bind antibody specific for protein. }\end{array}$ & $\begin{array}{l}\text { New York } \\
\text { University } \\
\text { (New York) }\end{array}$ & $\begin{array}{l}\text { Laal S, } \\
\text { Zolla-Pazner S }\end{array}$ & 4/19/2008 & $10 / 22 / 2009$ \\
\hline WO 2009127046 & $\begin{array}{l}\text { A new antibody or an antigen-binding fragment comprising a complemen- } \\
\text { tarity-determining region Gly-X1e-X2e-X3e-X4e-X5e-X6e-X7e-X8e-His } \\
\text { (SEQ ID NO. 65); useful for reducing the growth of prostate tumor cells. }\end{array}$ & $\begin{array}{l}\text { ProScan Rx } \\
\text { Pharma (Montreal) }\end{array}$ & $\begin{array}{l}\text { Cuello AC, } \\
\text { Gold P, } \\
\text { Melancon D, } \\
\text { Moffett S, } \\
\text { Saragovi HU }\end{array}$ & 4/14/2008 & $10 / 22 / 2009$ \\
\hline $\begin{array}{l}\text { WO } 2009099545 \text {, } \\
\text { US } 20090202557\end{array}$ & $\begin{array}{l}\text { A method of preparing crystals of an antigen-binding fragment (Fab) of } \\
\text { an antibody, comprising mixing the Fab with a reservoir solution com- } \\
\text { prising polyethylene glycol (PEG) and a buffer. }\end{array}$ & $\begin{array}{l}\text { Abbott Bioresearch } \\
\text { (Worcester, MA, } \\
\text { USA) Argiriadi MA, } \\
\text { Borhani DW, } \\
\text { Ghayur T, Wu C, } \\
\text { Xiang T }\end{array}$ & $\begin{array}{l}\text { Argiriadi MA, } \\
\text { Borhani DW, } \\
\text { Ghayur T, Wu C, } \\
\text { Xiang T }\end{array}$ & $1 / 30 / 2008$ & $\begin{array}{l}8 / 13 / 2009 \\
8 / 13 / 2009\end{array}$ \\
\hline WO 2009092014 & $\begin{array}{l}\text { Purifying a nonaggregated antibody or an immunoreactive antibody frag- } \\
\text { ment from an impure preparation containing the antibody or antibody } \\
\text { fragment, comprising contacting the impure preparation with an apatite } \\
\text { chromatography support. }\end{array}$ & Gagnon PS & Gagnon PS & $1 / 18 / 2008$ & $7 / 23 / 2009$ \\
\hline KR 2009011215 & $\begin{array}{l}\text { A surface expression vector expressing short-chain variable fragments } \\
\text { of porcine epidemic diarrhea virus (PEDV)-neutralizing antibody } \\
\text { encoded by a gene having a defined sequence of } 777 \text { amino acids } \\
\text { (Seq. id. no. 1) on membrane surface of bacteria; useful for expressing } \\
\text { short-chain variable fragments of PEDV-neutralizing antibody on the } \\
\text { surface of Escherichia coli, where the bacteria is useful in composition } \\
\text { for preventing or treating diarrhea. }\end{array}$ & $\begin{array}{l}\text { Republic of } \\
\text { Korea Ministry of } \\
\text { Agriculture and } \\
\text { Forestry (Seoul) }\end{array}$ & $\begin{array}{l}\text { Cho S, Hyun B, } \\
\text { Kim I, Kim S, } \\
\text { Pyo H, Song J }\end{array}$ & $7 / 25 / 2007$ & 2/2/2009 \\
\hline
\end{tabular}

Source: The status of each application is slightly different from country to country. For further details, contact Thomson Scientific, 1800 Diagonal Road, Suite 250 , Alexandria, Virginia 22314, USA. Tel: 1 (800) 337-9368 (http://www.thomson.com/scientific). 